\title{
Facile Synthesis Strategy to Create Mesoporous Magnetic Iron Oxides Using Pectin-Based Precursors
}

\author{
Filipe Q. Mariani, ${ }^{a}$ Mariane Dalpasquale, ${ }^{a}$ Sérgio H. Toma, ${ }^{b}$ Koiti Araki, ${ }^{b}$ \\ Helton J. Alves ${ }^{c}$ and Fauze J. Anaissi ${ }^{*, a}$
}

\author{
${ }^{a}$ Departamento de Química, Universidade Estadual do Centro-Oeste, 85040-080 Guarapuava-PR, Brazil \\ ${ }^{b}$ Instituto de Química, Universidade de São Paulo, Av. Prof. Lineu Prestes 748, Butantã, \\ 05508-000 São Paulo-SP, Brazil
}

'Setor Palotina, Universidade Federal do Paraná, 85950-000 Palotina-PR, Brazil

\begin{abstract}
Magnetic iron oxides are of great scientific and technological relevance. Therefore, herein, we report the research on developing methodologies for their sustainable and reproducible preparation. We discuss the synthesis of iron oxides involving citrus pectin as a source of energy (42 $\mathrm{MJ} \mathrm{kg}^{-1}$ ) to promote the formation of the magnetic phases. The method involved two simple steps: gelation of the pectin $\left(80^{\circ} \mathrm{C}, 4 \mathrm{~h}\right)$ with iron nitrate nonahydrate $\left[\mathrm{Fe}\left(\mathrm{NO}_{3}\right)_{3} \cdot 9 \mathrm{H}_{2} \mathrm{O}\right]$, and calcination $\left(600^{\circ} \mathrm{C}\right.$, $1 \mathrm{~h})$. X-ray diffraction indicated the major formation of hematite $\left(\alpha-\mathrm{Fe}_{2} \mathrm{O}_{3}\right)$ and ferrite phases. Microscopy images show materials with an average size below $50 \mathrm{~nm}$. Textural properties indicated pore sizes of 7-30 nm while magnetic measurements indicated the formation of soft and hard oxides (coercivity between 90 and $400 \mathrm{Oe}$ ) and high magnetization saturation (50 emu g-1).
\end{abstract}

Keywords: pectin, iron oxides, ferrites, magnetic, cytotoxicity

\section{Introduction}

The methods for preparation of magnetic materials are constantly evolving, particularly those based on iron oxides known as ferrites, one of the most intensively studied class of materials in the field of applied magnetic sciences. The weakly ferromagnetic properties of hematite $\left(\alpha-\mathrm{Fe}_{2} \mathrm{O}_{3}\right)$ at room temperature are different of those of the ferrimagnetic iron ferrite (magnetite, $\mathrm{FeO} \cdot \mathrm{Fe}_{2} \mathrm{O}_{3}$ ), cobalt ferrite $\left(\mathrm{CoO} \cdot \mathrm{Fe}_{2} \mathrm{O}_{3}\right)$, and nickel ferrite $\left(\mathrm{NiO} \cdot \mathrm{Fe}_{2} \mathrm{O}_{3}\right)$. On the other hand, spinels such as magnetite and maghemite, which are structurally equal, related to substituted cobalt or nickel ferrites, usually present a more complex inverse spinel cation distribution, where only half of octahedral and only $1 / 8$ of tetrahedral sites are filled (1/4 of octahedral positions are occupied by divalent ions while trivalent ions are located in $1 / 4$ of octahedral and $1 / 8$ of tetrahedral sites). ${ }^{1-4}$

Spinel ferrites $\left[\mathrm{M}^{2+} \mathrm{O} \cdot \mathrm{Fe}_{2} \mathrm{O}_{3}\right.$, where $\mathrm{M}=\mathrm{Fe}, \mathrm{Co}, \mathrm{Ni}, \mathrm{Cr}$, $\mathrm{Mn}$, etc.] have a broad range of applications, including hard and soft magnetic materials. ${ }^{5,6}$ These metal oxides, unlike alloys, present small Foucault's current loss, ${ }^{7}$ thereby

*e-mail: fjanaissi@gmail.com favoring applications as recording heads, converters, catalysts, molecules carriers, pigments, and magnetic fluids, among other applications. ${ }^{8-10}$ The most relevant among them is magnetite. Several synthetic routes have been reported for magnetite in the literature leading to materials with distinct magnetic, structural, morphologic, crystallite size distribution, electrical, chemical and physical properties. Examples of some of those synthetic routes include chemical co-precipitation, sol-gel method, forced hydrolysis, hydrothermal method, mediated surfactant or template synthesis, and biomimetic mineralization. ${ }^{11,12}$

Lately, because of the increasing environmental concerns, the development of fabrication processes with increasingly lower environmental impact, particularly on new materials, has received particular attention. Regarding the mediated nanostructured oxides, biopolymers is one of the most interesting topics, as far as the principles of green chemistry are concerned. ${ }^{13}$ Among biopolymers, the one of most interest is pectin taken into account its abundance and low cost. ${ }^{14}$ Pectin is a polysaccharide constituting about one-third of the dry weight of cell walls of many plants. For example, peels and apple pulps are low-cost by-products of food industry that can be used as an energy source on the preparation of new materials. 
Pectins are mainly composed by D-galacturonic acid (GalA) units linked by 1,4-glycosidic bonds, and exhibit carboxylic acid groups throughout the chain, that can be used to bind transition metal ions (Scheme 1). Also, they have a high power of colloid formation by gelification; property that depends directly on the source and the degree of esterification. If a pectin has more than $60 \%$ of its carboxylic groups esterified with methyl groups, it is characterized as being a high-methoxyl (HM) pectin, ${ }^{13,15}$ and has lower metal ion coordination capability.

The pectin chain folds approaching distant carboxylate groups creating chelating coordination sites, making them able to capture transition metal ions in aqueous solution. Pectins are extraordinarily stable in solution at temperatures from 10 to $80^{\circ} \mathrm{C}$ and in a pH range of 2.5 to 4.0 , making them very useful in various fields of applied science. ${ }^{16,17}$ However, to the best of our knowledge, there is no report dealing with the use of pectin for the production of porous and nanostructured materials.

This paper describes a facile method, ${ }^{18}$ to prepare mesoporous ferrite using citrus pectin to produce the gel precursor, which after calcination generates Fe-MIO, $\mathrm{Fe}_{80} \mathrm{Co}_{20}$-MIO, and $\mathrm{Fe}_{80} \mathrm{Ni}_{20}$-MIO, where MIO stands for magnetic iron oxide. The MIOs were duly characterized in order to check for the influence of their stoichiometry on the composition of the materials that exhibited unique magnetic, morphologic, and structural properties suggesting potential as pigments.

\section{Experimental}

\section{Materials and reagents}

The magnetic iron oxides (MIOs) were prepared by using the following commercially available reagents in analytical grade, purchased from Vetec Fine Chemicals and Sigma-Aldrich Company: iron(III) nitrate nonahydrate
$\left[\mathrm{Fe}\left(\mathrm{NO}_{3}\right)_{3} \cdot 9 \mathrm{H}_{2} \mathrm{O}\right]$, cobalt(II) nitrate hexahydrate $\left[\mathrm{Co}\left(\mathrm{NO}_{3}\right)_{2} \cdot 6 \mathrm{H}_{2} \mathrm{O}\right]$, and nickel(II) nitrate hexahydrate $\left[\mathrm{Ni}\left(\mathrm{NO}_{3}\right)_{2} \cdot 6 \mathrm{H}_{2} \mathrm{O}\right]$. The citrus pectin (PA grade) with approximately $67.3 \%$ of its carboxylic groups esterified by methoxyl groups, ${ }^{19}$ consisting of poly(galacturonic acid) connected by $1,4-\beta$-glucoside bonds. The minimum formula is $\left[\mathrm{C}_{5} \mathrm{H}_{7} \mathrm{O}_{4}(\mathrm{COOH})_{m-1}\left(\mathrm{COOCH}_{3}\right)_{m}\right]_{n}$, where $m$ refers to the degree of esterification as deduced from the formula $(14.02 m+176.13)$ and $n$ is the average number of repeating units. ${ }^{20}$ The pectin used in the experiments has a molecular weight of about $185.57 \mathrm{~g} \mathrm{~mol}^{-1}$. All reagents were used as received. The solutions were prepared using ultrapure water from a Quimis Model Q842 reverseosmosis system.

\section{Synthesis of the magnetic iron oxides (MIO)}

Initially, a solution was prepared by adding 4.0 grams of citrus pectin in $200 \mathrm{~mL}$ of preheated water $\left(60{ }^{\circ} \mathrm{C}\right)$ generating a $2 \%$ solution $(\mathrm{m} / \mathrm{m})$. Then, $20.79 \mathrm{~g}$ of iron nitrate dissolved in $20 \mathrm{~mL}$ of water were added under constant stirring and heating. The solution was kept at $80{ }^{\circ} \mathrm{C}$ for about 2 hours until the volume was reduced to its half. The gelation was then complete; the colloid was calcined in a muffle oven at $600{ }^{\circ} \mathrm{C}$, leading to the formation of Fe-MIO. For the preparation of other ferrites, it was added an equal volume $(20 \mathrm{~mL})$ of ferric nitrate $(20.79 \mathrm{~g})$ plus cobalt nitrate $(6.81 \mathrm{~g})$ or nickel nitrate $(6.82 \mathrm{~g})$, leading to the formation of FeCo-MIO or FeNi-MIO, respectively.

The complexation of the transition metal ions is proposed to take place forming an egg-box-shaped arrangement characteristic for HM-pectin, ${ }^{15}$ as shown in Scheme 1 . The relatively large chains with a high degree of esterification and relatively separated coordination sites is essential to the formation of homogeneous and translucent gel precursors. ${ }^{21,22}$ These were dried, and the temperature

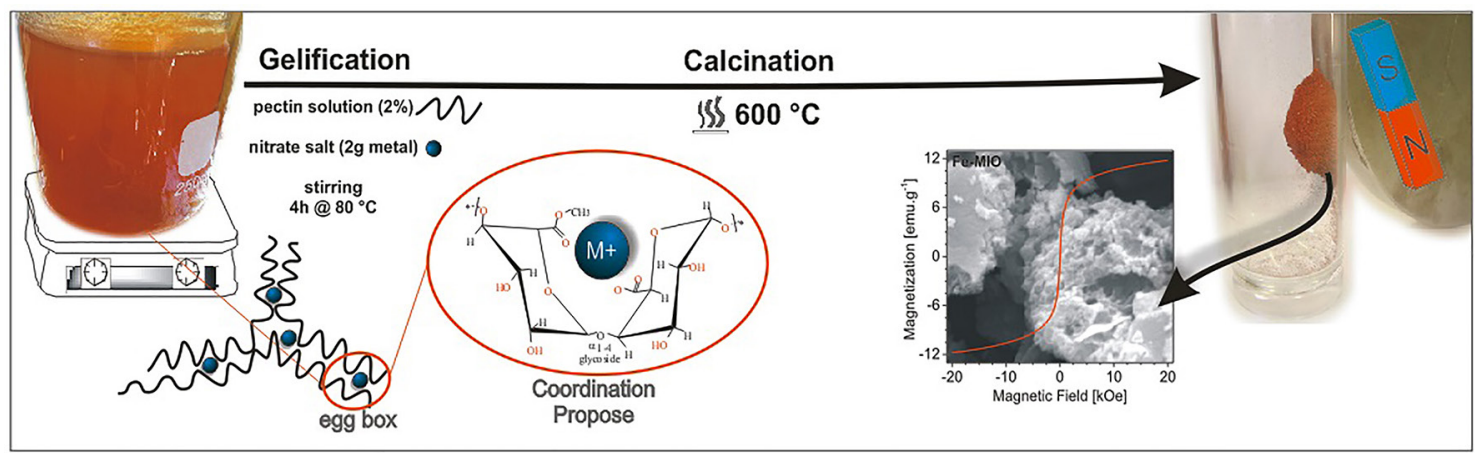

Scheme 1. Mesoporous iron oxides and ferrites based on calcination $\left(600^{\circ} \mathrm{C}\right)$ of citrus pectin gel precursors. Left: scheme showing the possible coordination environment around transition-metal ions in citrus pectin with high methoxylation content (egg-box-shaped containment of the ions). Right: powder attracted by a permanent magnet $\left(\mathrm{Nd}_{2} \mathrm{Fe}_{14} \mathrm{~B}\right)$. The predominant component of the reddish solid is hematite $\left(\alpha-\mathrm{Fe}_{2} \mathrm{O}_{3}\right)$ with magnetic profile due to mass ratio hematite:magnetite of $14: 1$, and sponge-like structure. 
was increased up to $600{ }^{\circ} \mathrm{C}$ in a furnace using a heating ramp of $10^{\circ} \mathrm{C} \mathrm{min}^{-1}$ generating a soft and easily pulverized solid labeled "puff" after combustion. The very fast reaction and associated high temperatures concomitantly with the gas release $\left(\mathrm{CO}, \mathrm{CO}_{2}\right.$, and water vapor) are responsible for controlling the degree of crystallinity and morphology of the resultant materials. The magnetic monometallic (Fe-MIO) and bimetallic (FeCo-MIO and FeNi-MIO) were prepared using the above-described procedure involving a coordination/gelation step followed by calcination.

\section{Characterization}

X-ray diffraction (XRD) was performed on a Bruker D2 Phaser diffractometer equipped with a copper cathode $(\mathrm{Cu} \mathrm{K} \alpha, \lambda=1.541838 \AA$ ), operating at $30 \mathrm{kV}$ and $10 \mathrm{~mA}$, using a working window of $2^{\circ}$ to $90^{\circ}(2 \theta)$ and at a scanning rate of $0.2^{\circ} \mathrm{s}^{-1}$. The collected data were numerically treated using the EVA software (Bruker version 1.1) and the diffraction peaks indexed according to ICDD-PDF2-2009 cards. The thermal behavior was recorded in a Seiko Model 6300 simultaneous thermal analyzer (STA). The samples were heated in aluminum pans from 30 to $1200{ }^{\circ} \mathrm{C}$, using a heating rate of $20^{\circ} \mathrm{C} \mathrm{min}^{-1}$ in compressed-air atmosphere $\left(0.2 \mathrm{~L} \mathrm{~min}^{-1}\right)$. Scanning electron microscopy (SEM) images were registered in a JEOL FEG-JSM-7401F equipment. The specific area, average pore size, and pore volume was determined by nitrogen adsorption. The adsorption/ desorption isotherms were recorded at liquid nitrogen temperature (77 K) using a Quantachrome Nova 2000e equipment and samples pre-treated at $180{ }^{\circ} \mathrm{C}$ under vacuum. The specific area was determined using the Brunauer-Emmett-Teller (BET) method with $p / p_{0} \leq 0.3$. The pore volume and pore diameter were determined by the Barrett-Joyner-Halenda (BJH) adsorption method.

The near-infrared (NIR) spectra were obtained in a fiber optic spectroradiometer model Fieldspec 3 from Analytical Spectral Devices. The average of twenty spectra was recorded in the range of $900-2500 \mathrm{~nm}$ to improve the signal to noise ratio, resolution of $1 \mathrm{~cm}^{-1}$. The Raman spectra were recorded using a confocal Raman microscope (Witec Alpha 300R), using a $532 \mathrm{~nm}$ laser (power was set to $0.2 \mathrm{~mW} \mathrm{~cm}^{-2}$ ) and a $100 \times$ objective. Electronic spectra were obtained using an Ocean Optics spectrophotometer (Model USB 2000), equipped with a tungsten-halogen lamp (UV-Vis, $350-720 \mathrm{~nm}$ ) connected to a fiber-optic probe operating in diffuse reflectance mode. From the electronic spectra, the energy band gap $\left(\mathrm{E}_{\mathrm{BG}}\right)$ was calculated by Tauc method; the spectra were converted using reflection $R$ in absorption coefficient with Kubelka-Munk equation $\left(f(R)=\frac{(1-R)^{2}}{2 R}\right)$.
Graphs were plotted in $(f(R) \times \mathrm{h} v)^{\mathrm{n}}$ as a function of energy (hv) and $\mathrm{E}_{\mathrm{BG}}$ calculated by linear regression. ${ }^{18}$

The electronic paramagnetic resonance (EPR) were obtained with a Bruker equipment, model EMX operating frequency of ca. $9.5 \mathrm{GHz}$ (X-band) with frequency modulation of $100 \mathrm{kHz}$, amplitude modulation of $8 \mathrm{kG}$ and microwave power of $20 \mathrm{MW}$. Magnetic properties were measured with a vibrating sample magnetometer (VSM), with maximum applied field of $20 \mathrm{kOe}$. In both cases (EPR and VSM), powder samples were placed in capillary tubes parallel to the field, and the measurements were performed at $300 \mathrm{~K}$.

In vitro, cytotoxic effects were evaluated using erythrocytes from healthy volunteers. Blood samples were collected in heparin, centrifuged, and the plasma and leukocytes removed by aspiration. The erythrocytes were then suspended in $10 \mathrm{mM}$ sodium phosphate buffer $(\mathrm{pH}=7.4)$ and incubated with 1,5 , and $10 \mathrm{mg}$ of MIO for 4 and 24 hours at $37{ }^{\circ} \mathrm{C}$ in a shaker. Subsequently, the suspensions were centrifuged, and the amount of hemoglobin released into the supernatant due to hemolysis was determined spectrophotometrically. The measurements were carried out at $540 \mathrm{~nm}$ in a Max 190 Molecular Devices Spectra UV-Vis spectrophotometer.

\section{Results and Discussion}

The novel synthetic route to create mesoporous iron oxides (in this text, referred to as magnetic iron oxides, MIOs) resulted from a combination of citrus pectin and transition metal ions nitrates followed by a gelation process $\left(80^{\circ} \mathrm{C}\right)$ and subsequent calcination $\left(600^{\circ} \mathrm{C}\right)$. The homogeneous gel associated with its high organic and energy content favored the formation of porous oxides, but without extensive nanoparticles sintering. Thus, the products were obtained as finely divided powders, without needing further processing in a mortar or mill, after the calcination in the muffle furnace. Similar methods of preparation are found in the literature. ${ }^{19}$ However, they involve a greater number of reagents (i.e., oxidizing or reducing agents, binders, organic solvents, polymerizing agents) and require special handling conditions (i.e., controlled atmosphere and humidity) or a greater number of steps (i.e., mixing, heating, volume reduction, grinding, sieving) ${ }^{23-25}$ This pectin-induced method is a much simpler and inexpensive alternative, which adds value to the organic residues from the fruit pulp industry.

\section{Structural and thermal properties}

The powder XRD patterns shown in Figure 1 shows typical characteristics of crystallographic phases 
corresponding to iron oxides. Fe-MIO (Figure 1a) was indexed as a mixture of phases according to ICDD cards to hematite (PDF 00-033-0664) and magnetite (PDF 01-071-6336). The hematite is characterized by two reflection peaks at $2 \theta 24^{\circ}(012)$ and $33^{\circ}(104)$ in a rhombo.H.axes unit cell with the lattice parameters $a=5.0356 \AA$ ( 167$), c=13.7489 \AA$ pointing to R-3c space group. On the other hand, magnetite is characterized by a reflection at $2 \theta 36^{\circ}(311)$ in a cubic unit cell with the lattice parameters $a=8.3778 \AA$ (227) of the Fd-3m space group. From the characteristic peaks, it was estimated a mass ratio hematite:magnetite of $14: 1$, which is sufficient to explain the magnetic behavior of the Fe-MIO.

The $\mathrm{Fe}_{0.8} \mathrm{Co}_{0.2}$-MIO (Figure 1b) was identified and indexed as cobalt ferrite (PDF card No. 01-070-8729) in

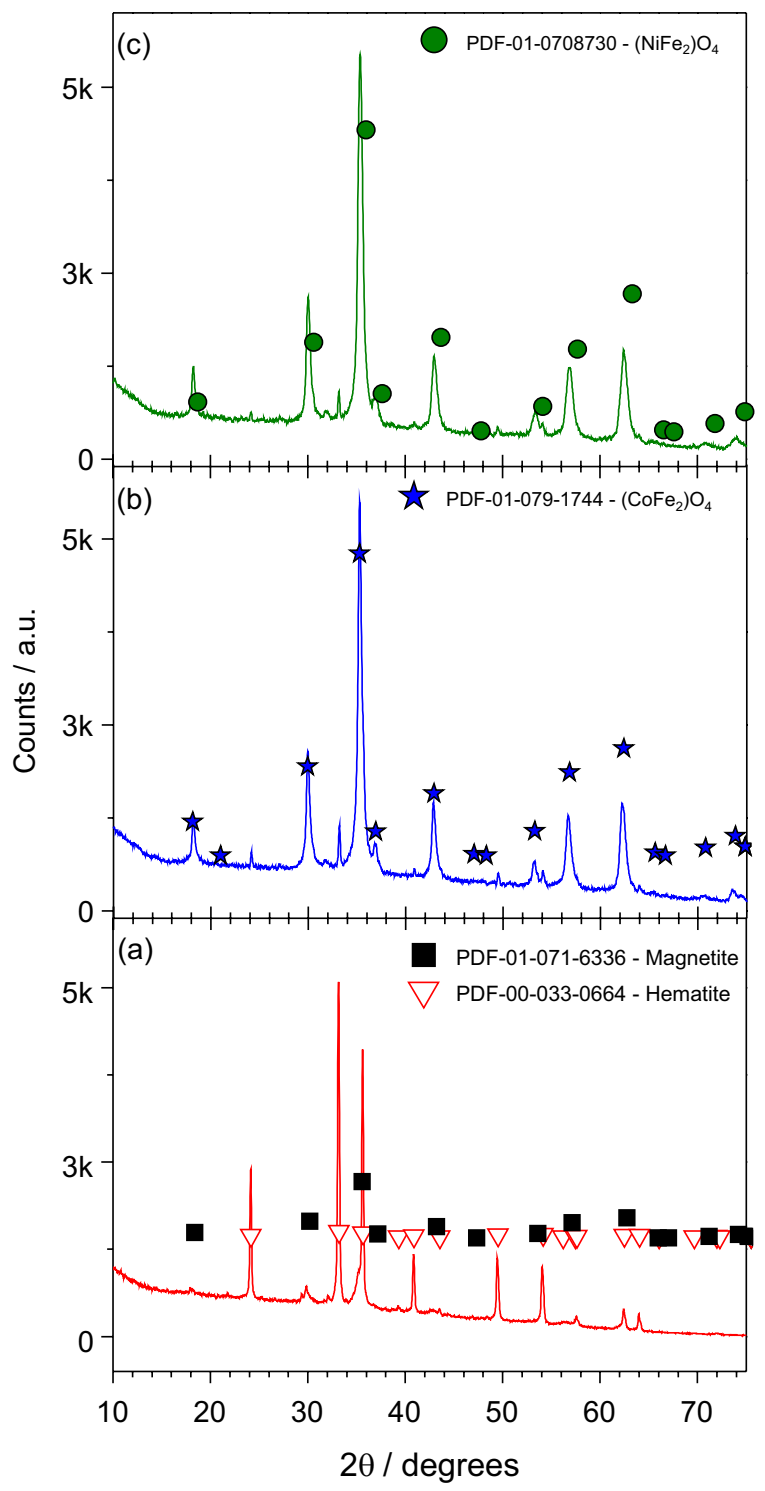

Figure 1. Powder XRD patterns for (a) Fe-MIO containing the $\alpha-\mathrm{Fe}_{2} \mathrm{O}_{3}$ (hematite) as the major phase. The dominant phases for the (b) cobalt and (c) nickel ferrites are marked. a cubic unit cell with the lattice parameters $a=8.4030 \AA$ (227) of the $\mathrm{Fd}-3 \mathrm{~m}$ space group. The $\mathrm{Fe}_{0.8} \mathrm{Ni}_{0.2}$ - $\mathrm{MIO}$ (Figure 1c) was identified and indexed as nickel ferrite (PDF card No. 01-070-8730) in a cubic unit cell with the lattice parameters $a=8.3420 \AA$ (227) also of the Fd-3m space group. For the two ferrites (cobalt and nickel) prevail intense peaks at $2 \theta 35.4^{\circ}(311), 30^{\circ}(220)$; while the peaks at $57^{\circ}(511)$ and $62.5^{\circ}(440)$ are more intense than for Fe-MIO. From indexing the phases, it is possible to identify the degree of crystallinity and mean coherence length (MCL) by the Scherrer equation and full-width at half-maximum (FWHM) parameters. ${ }^{25}$ The Fe-MIO has higher crystallinity (84\%) followed by cobalt ferrite $(21 \mathrm{~nm})$ whereas nickel ferrites $(16 \mathrm{~nm})$ exhibited the lowest MCL and degree of crystallinity (77\%). The degrees of crystallinity for the MIO's decreased when a second metal ion was added as expected for the higher complexity and the longer time for the components to diffuse and crystallize. This difference in crystallinity also can be associated with the formation of smaller crystallites during the inhomogeneous calcination process. ${ }^{26}$

The energy supplied by combustion of pectin during MIO preparation was estimated in $42 \mathrm{MJ} \mathrm{kg}^{-1}$ by integration of the exothermic peaks in the differential DTA curve (gray area in Figure 2a).

The three MIOs have similar thermal behavior (Figure 2b) as characterized by three distinct events
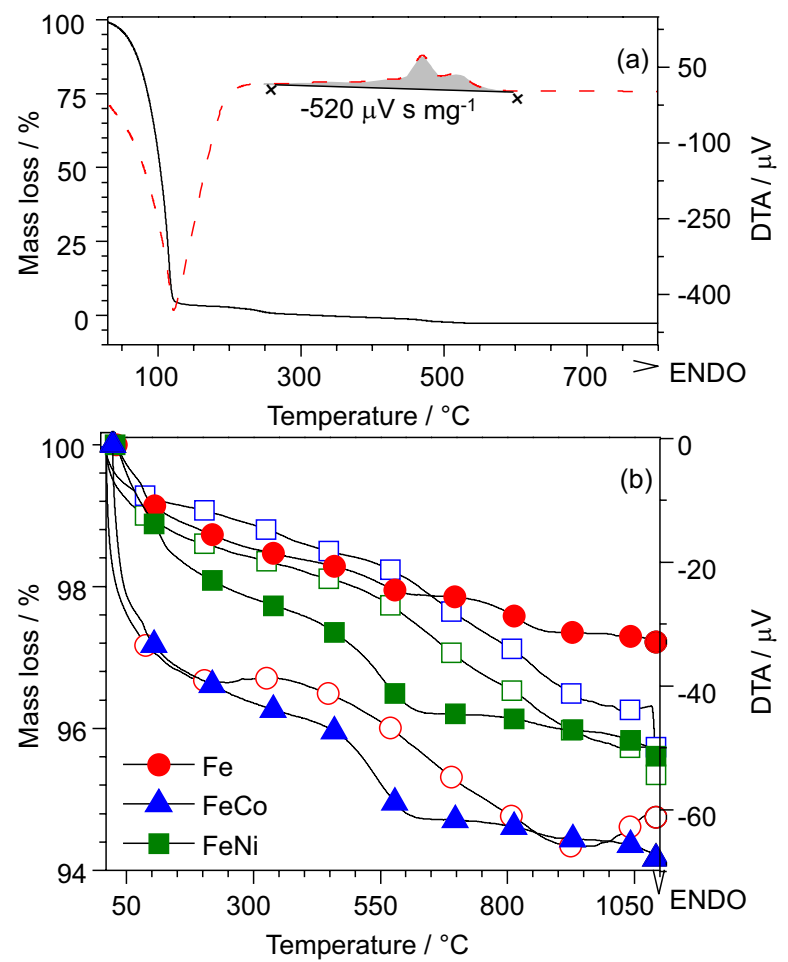

Figure 2. Thermal behavior of (a) pectin gel used as a reference for determination of combustion energy (fuel) and (b) MIOs show similar behavior for both, dehydration and loss of the residual organic material. All thermal curves were performed in a dynamic air atmosphere at $10{ }^{\circ} \mathrm{C} \mathrm{min}-1$. 
(mass loss), associated with exothermic processes or phase transitions (DTA), and a total weight loss ranging from 2.8 to $5.8 \%$, depending on the transition metal ion.

The first event was attributed to dehydration, with the mass variation calculated from the initial $\left(30^{\circ} \mathrm{C}\right)$ and final $\left(300{ }^{\circ} \mathrm{C}\right)$ temperatures $\left(\mathrm{T}_{\text {offset }}=150{ }^{\circ} \mathrm{C}\right)$. The second event $\left(\mathrm{T}_{\text {offset }}=400{ }^{\circ} \mathrm{C}\right)$ was due to thermal decomposition or combustion of residual organic material; the third event $\left(\mathrm{T}_{\text {offset }}=915^{\circ} \mathrm{C}\right)$ was typical of a phase transition. The Fe-MIO showed the lowest amount of residual organic material (1\%), reinforcing the conclusions drawn from the respective XRD, which indicated a higher degree of crystallinity. The cobalt and nickel ferrites were found to contain only about $2 \%$ organic impurities, wich may be responsible for lowering the degree of crystallinity. Noteworthy was the absence of thermal events (DTA curve) that can be associated with a mixture of phases.

\section{Textural and morphological properties}

The MIO's surface area was analyzed by nitrogen physisorption. The results of BET curves are consistent with type-IV adsorption and desorption hysteresis in the 0 to 1 torr range, typical of mesoporous materials (Figure 3a).
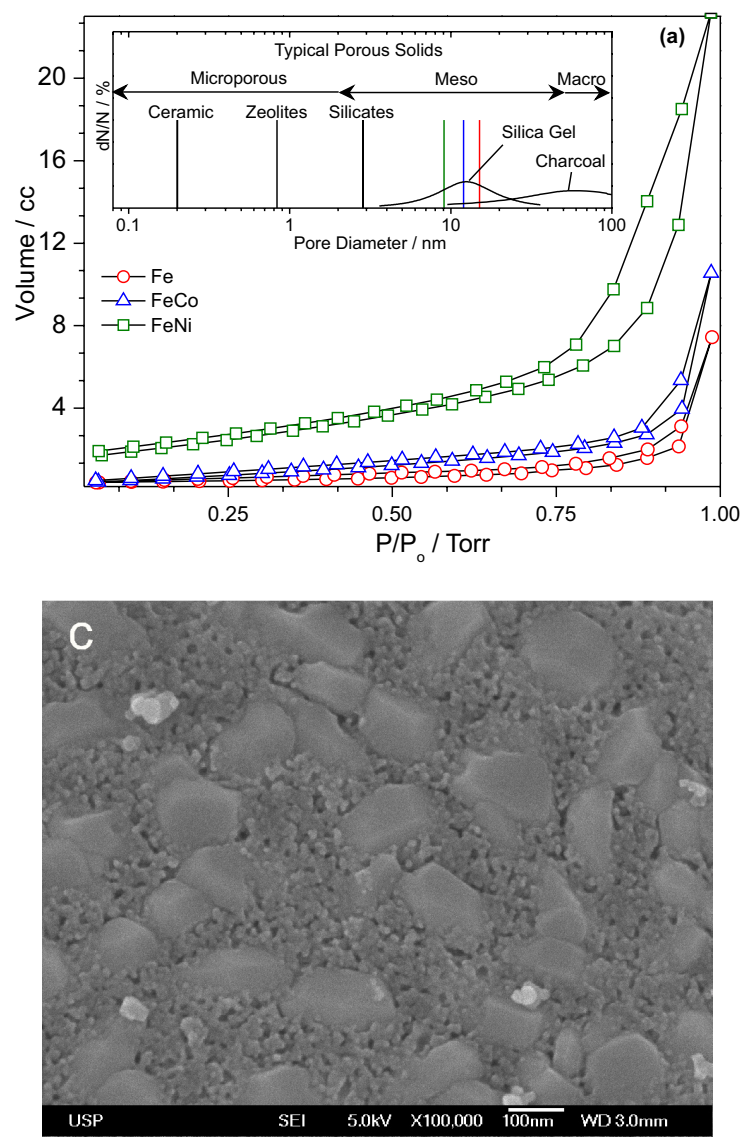

The pore sizes were calculated using the BJH method with distribution in the 7 to $30 \mathrm{~nm}$. Surface area measurements by BET can be used to estimate the relative humidity and also to understand the porous nature. ${ }^{26} \mathrm{Fe}-\mathrm{MIO}$ was found to have a higher pore size $(15.1 \mathrm{~nm})$ and smaller relative humidity $(1.06 \%)$ than other ferrites. For cobalt ferrite, pore size was estimated to be $12.9 \mathrm{~nm}$ involving $1.6 \%$ relative humidity, whereas the pore size of nickel ferrite was estimated to be $9.1 \mathrm{~nm}$ and $3.2 \%$ relative humidity. Those pore size values are larger than for zeolites and silicates used in heterogeneous catalysis, ${ }^{26}$ but analogous to that found in silica gel, ${ }^{27}$ as shown in Figure 3a.

The size and shape of the particles or agglomerates can lead to different properties of each material, ${ }^{28}$ as in the case of MIO which morphology and particle size are different. SEM image of the Fe-MIO (Figure 3b) shows agglomerates in the form of typical ellipsoids of $\alpha-\mathrm{Fe}_{2} \mathrm{O}_{3}$ phase, with particle sizes ranging from 30 to $100 \mathrm{~nm}$. These characteristics are similar to those reported in the scientific literature for nanosized mesoporous materials containing iron oxide. ${ }^{28}$ SEM image of the FeCo-MIO (Figure 3c) shows agglomerates of 60 to $200 \mathrm{~nm}$ and particles smaller than $20 \mathrm{~nm}$, formed by the phase identified by XRD as being cobalt ferrite (Figure 1b). From SEM images of the
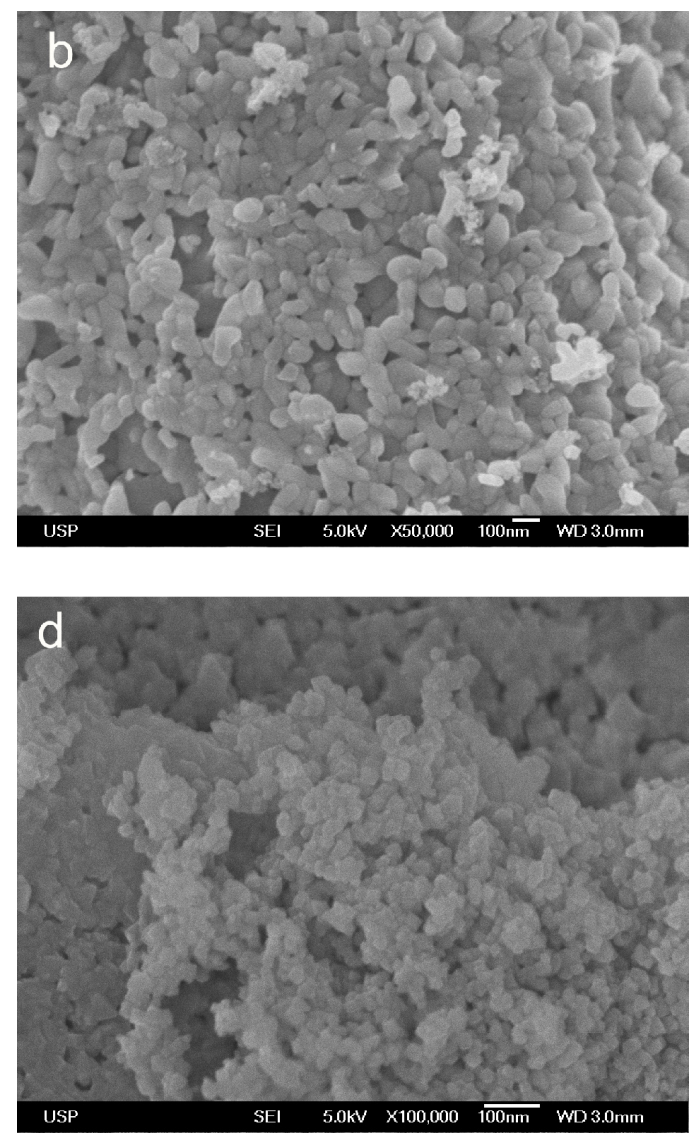

Figure 3. (a) BET-surface-area analysis showing the typical profiles of mesoporous materials. SEM images of (b) Fe-MIO; (c) FeCo-MIO and (d) FeNi-MIO. 
FeNi-MIO (Figure 3d), the particles have polyhedral shapes and a particle size between 10 and $100 \mathrm{~nm}$. In general, the MIO's obtained with average sizes lower than $50 \mathrm{~nm}$, can be classified as nanomaterials or as nanometric materials.

\section{Spectroscopic behavior}

Electronic and vibrational spectroscopies are relevant to the phenomena involved in atomic and molecular interactions as well as in charge transfer processes. The Fe-MIO and ferrites spectra in the NIR region showed a characteristic low-intensity band at $1950 \mathrm{~nm}\left(5130 \mathrm{~cm}^{-1}\right)$, attributed to water $\mathrm{O}-\mathrm{H}$ bond stretching mode (Figure 4a). ${ }^{29}$ Also of significance is the absence of sharp bands that are characteristic of $\mathrm{C}-\mathrm{C}$ and $\mathrm{C}-\mathrm{H}$ bonds in the $1000-1700 \mathrm{~cm}^{-1}$ range and eventual $\mathrm{M}-\mathrm{C}$ and $\mathrm{M}-\mathrm{N}$ bonds in the region below $1000 \mathrm{~cm}^{-1}$, suggesting that only little amounts of organic material are left over in the ceramic materials after calcination at $600{ }^{\circ} \mathrm{C} .{ }^{30}$
In fact, the Fe-MIO Raman spectrum is similar to that of a material with predominant hematite phase $\left(\mathrm{D}^{6}\right)$ with seven well-defined active phonons: two $\mathrm{A}_{1 \mathrm{~g}}$ modes (225 and $500 \mathrm{~cm}^{-1}$ ) and five $\mathrm{E}_{\mathrm{g}}$ modes (a shoulder at $248 \mathrm{~cm}^{-1}$, two overlapping bands at 293 and $299 \mathrm{~cm}^{-1}$, and two bands at 410 and $611 \mathrm{~cm}^{-1}$ ). There was still a low-intensity band at $1320 \mathrm{~cm}^{-1}$ attributed to the formation of a magnon due to the presence of nearby antiparallel spins in hematite. The additional broad, low-intensity bands at 670 and $512 \mathrm{~cm}^{-1}$ have been assigned to magnetite (present in small amounts) phonons with $\mathrm{A}_{\mathrm{lg}}$ and $\mathrm{F}_{2 \mathrm{~g}}$ symmetry, respectively. ${ }^{29,31}$

The Raman spectra of ferrites FeCo-MIO and FeNi-MIO were very similar and showed five active phonons around 200 and $300 \mathrm{~cm}^{-1}$, assignable to the $T\left(F_{2 g}\right)$ and v2 $\left(\mathrm{E}_{\mathrm{g}}\right)$ modes, respectively. They also had further vibrational modes at 475,600 , and $700 \mathrm{~cm}^{-1}$ assigned to v4 $\left(\mathrm{F}_{2 \mathrm{~g}}\right), \mathrm{v} 3\left(\mathrm{~F}_{2 \mathrm{~g}}\right)$, and v1 $\left(\mathrm{A}_{1 \mathrm{~g}}\right)$ modes, respectively. ${ }^{32}$ The iron ferrites showed a magnon band at $1350 \mathrm{~cm}^{-1}$, associated with the collective spin movement. ${ }^{33}$ All active vibrational
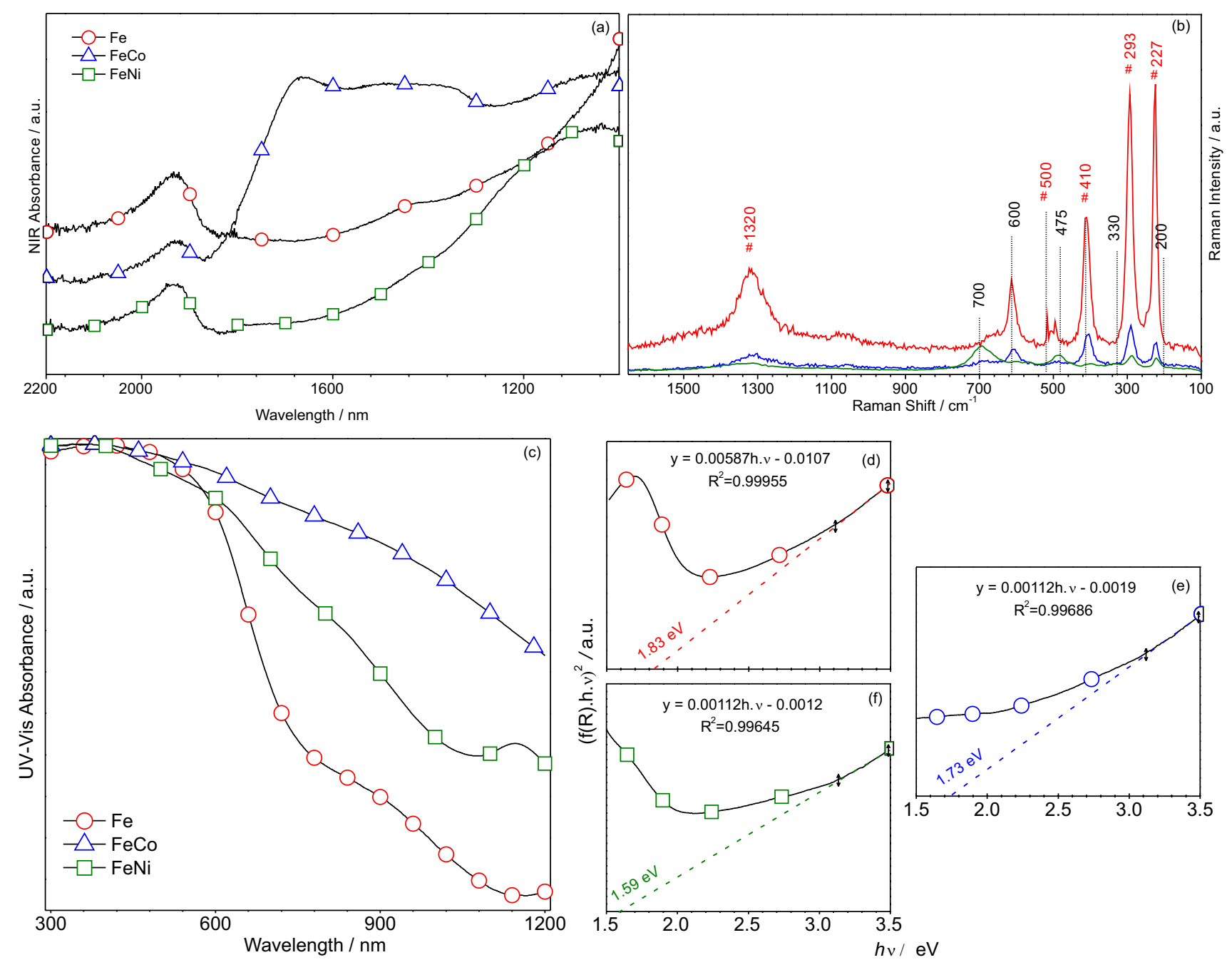

Figure 4. Spectra of (a) NIR with absorbance between $0<$ abs $<1$; (b) Raman obtained with a blue laser (473 nm); (c) the UV-Vis absorbance mode, and (d), (e) and (f) direct optical-gap calculations using the TAUC method. 
modes of the binary oxides were characteristic of crystalline materials belonging to the cubic group. ${ }^{34}$

Figure $4 \mathrm{c}$ shows the UV-Vis spectrum of MIOs. The absorption spectrum of Fe-MIO (Figure 4c, circle line) shows two bands at 550 and $660 \mathrm{~nm}$, typical of $\alpha-\mathrm{Fe}_{2} \mathrm{O}_{3}$. The transition type $6 \mathrm{~A}_{1} d-d>4 \mathrm{~T}_{2}(4 \mathrm{G})$ occurred between 400 and $600 \mathrm{~nm}$, and is consistent with the first band centered at $550 \mathrm{~nm}$. The ligand-to-metal transition and the pair resulting from the interaction between the two metal centers ( $\mathrm{Fe}-\mathrm{Co}$ or $\mathrm{Fe}-\mathrm{Ni}$ ) occurred in the region between 600 and $750 \mathrm{~nm}$, attributed to $6 \mathrm{~A}_{1}>4 \mathrm{~T}_{2}(4 \mathrm{G})$, as observed at $660 \mathrm{~nm}$. The small amount of magnetite identified by XRD was not enough to change the hematite electronic spectrum significantly.

The $d$ - $d$ transitions allow calculating the band-gap energy in the UV-Vis absorption spectrum for hematite and magnetite. Thus, mathematical tools must assist the interpretation of data. For instance, the Tauc method can be used to determine the energy of the band gap transitions (photoelectric energy) (Figures 4d, 4e, 4f). ${ }^{35}$ Typically $E_{\mathrm{BG}}$ values of pure hematite are found in the 2.14 to $2.22 \mathrm{eV}$ range $(580-558 \mathrm{~nm})$, but for mixed phase materials, the value might be lower. ${ }^{36}$ In fact, the $\mathrm{E}_{\mathrm{BG}}$ for the hematite-rich sample with $6.7 \%$ of magnetite, as determined by XRD analysis, was found to be $1.83 \mathrm{eV}$, as shown in Figure $4 \mathrm{~d}$. The similar tendency was observed for the nickel-ferrite spectrum (Figure 4f) that exhibited two absorption bands at 550 and $650 \mathrm{~nm}$, and the respective $\mathrm{E}_{\mathrm{BG}}$ was evaluated as $1.59 \mathrm{eV}$. Cobalt ferrite (Figure 4e) showed a band at $715 \mathrm{~nm}$ $(1.73 \mathrm{eV})$ indicating a higher effect of $\mathrm{Co}^{2+}$ than $\mathrm{Ni}^{2+}$ in decreasing the band-gap energy, probably due to an inverse spinel structure where $\mathrm{Co}^{3+}$ ions can occupy tetrahedral sites. In fact, the $\mathrm{E}_{\mathrm{BG}}$ value of $1.73 \mathrm{eV}$ is in agreement with

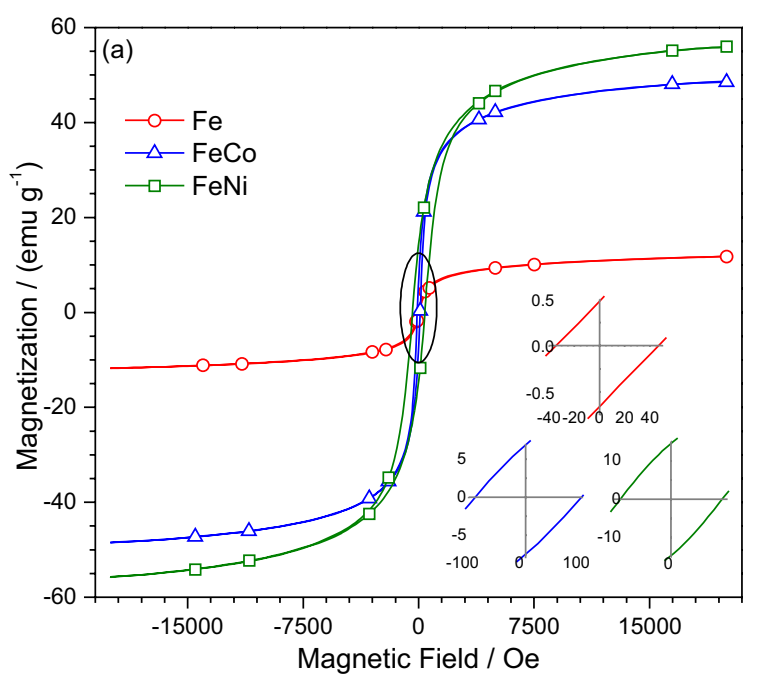

the value reported in the literature $\left(\mathrm{E}_{\mathrm{BG}}=1.70 \mathrm{eV}\right)$ for the $4 \mathrm{~A}_{2}$ to $4 \mathrm{~T}_{1}(\mathrm{P})$ transition, typical of $\mathrm{Co}^{3+}$ ions in tetrahedral sites, thus reinforcing that hypothesis. ${ }^{35}$

\section{Magnetic properties}

The isothermal behavior of the magnetization under applied magnetic field was determined from VSM measurements at room temperature and $20 \mathrm{kOe}$ range. Figure 5a shows magnetic hysteresis loops in the plot of magnetization as a function of the applied field. Parameters such as saturation magnetization $M_{\mathrm{s}}$ (maximum magnetization value), remanent magnetization $M_{\mathrm{r}}$ (magnetization at zero field), coercivity $H_{\mathrm{c}}$ (necessary magnetic field to reduce the magnetization to zero), and quadrature rate $\left(M_{\mathrm{s}} / M_{\mathrm{r}}\right)$, were determined from the magnetic hysteresis curve. All those parameters indicated that the Fe-MIO has small remanent magnetization, characteristic of soft magnetic materials.

The Fe-MIO exhibited low coercivity (40 Oe) and low saturation magnetization, characteristic of

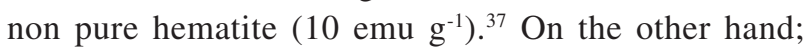
FeCo-MIO showed higher coercivity (93 Oe) and saturation magnetization (50 emu $\mathrm{g}^{-1}$ ), but lower than that found for FeNi-MIO (400 Oe and $60 \mathrm{emu} \mathrm{g}^{-1}$, respectively). The saturation magnetization is intrinsically dependent on the type of material, the average number of magnetic domains per grain and thus on crystallites size. ${ }^{38}$ In the case of ferrites, the magnetization is mainly due to the spins associated with $\mathrm{Fe}^{2+}$ in octahedral sites whose magnetic moment is not canceled out by coupling with $\mathrm{Fe}^{3+}$ spins in tetrahedral sites. Hematite has a low saturation magnetization as compared with cobalt and nickel ferrites such that the measured magnetization probably is due to

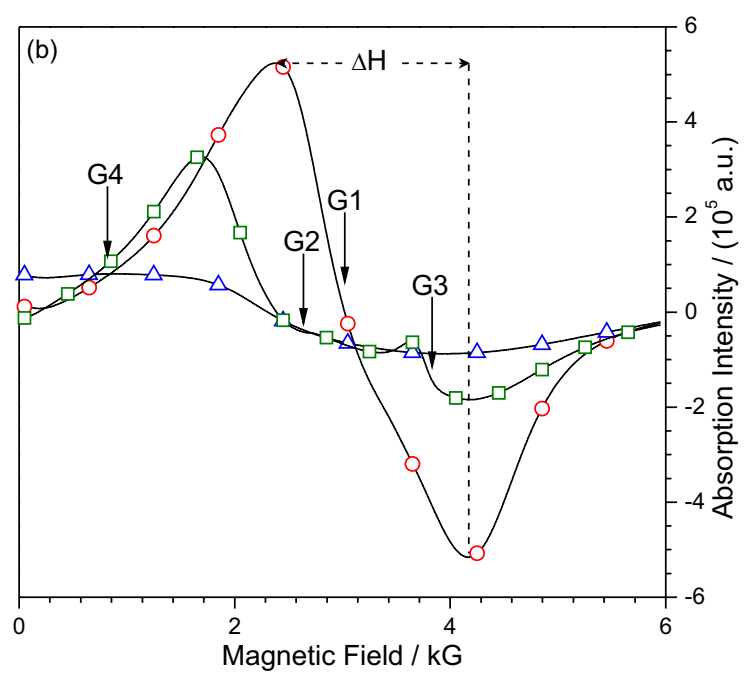

Figure 5. (a) Typical magnetic conduct of soft ferromagnetic materials (Fe-MIO) with small remanent magnetization. The inset shows the maximum remaining magnetization; (b) the EPR spectra show the typical resonant conduct of paramagnetic materials; the curve shows symmetry (circles), and the G1-G4 points are the inflections used to determine $\mathrm{g}$ factor of each oxide. 
Table 1. Structural (XRD), magnetic (VSM) and morphological (BET and SEM) parameters of magnetic iron oxides (MIO)

\begin{tabular}{|c|c|c|c|c|c|c|}
\hline \multirow{2}{*}{ MIO sample } & \multicolumn{3}{|c|}{ XRD } & \multirow{2}{*}{$\begin{array}{c}\text { VSM } \\
\Delta \mathrm{Hc} / \mathrm{Oe}\end{array}$} & \multirow{2}{*}{$\begin{array}{c}\text { BET } \\
\text { Pore size / nm }\end{array}$} & \multirow{2}{*}{$\begin{array}{c}\text { SEM } \\
\text { Particle size / nm }\end{array}$} \\
\hline & Space group & Crystallite size / nm & Cristallinity / \% & & & \\
\hline $\mathrm{Fe}$ & Fd-3m (227) & 41.0 & 84.1 & 40 & 15.1 & 65 \\
\hline FeCo & R-3m (166) & 21.0 & 77.0 & 93 & 12.9 & 90 or 10 \\
\hline $\mathrm{FeNi}$ & Fd-3m (227) & 16.3 & 76.3 & 400 & 9.1 & 18 \\
\hline
\end{tabular}

the presence of magnetite $(6.7 \%)$. The $H_{\mathrm{c}}$ of hematite, with particle sizes between 0.01 and $20 \mu \mathrm{m}$, was 30 to 400 Oe, but can decrease to 2.5 Oe in mixed ferrites presenting a typical antiferromagnetic hysteresis loop. ${ }^{39}$

The magnetization curve of Fe-MIO resembles that of superparamagnetic materials at room temperature, as expected for $\alpha-\mathrm{Fe}_{2} \mathrm{O}_{3}$ nanoparticles and magnetite nanoparticles. ${ }^{40}$ In this case, the magnetic dipoles of magnetite would not influence the orientation of hematite spins in the crystalline network. ${ }^{41}$ Table 1 summarizes the structural, morphological and magnetic properties of iron oxide and ferrites.

Magnetic properties can be calculated from the respective EPR spectrum shown in Figure 5b. It features a pattern of two lines at room temperature $(300 \mathrm{~K})$, and the Fe-MIO (Figure 5b, circle) shows a paramagnetic profile. ${ }^{42}$ For $\alpha-\mathrm{Fe}_{2} \mathrm{O}_{3}$ (Figure 5b, G1) is expected to exhibit a strong resonance band $(\Delta \mathrm{H}=1800 \mathrm{G})$, indicating magnetic anisotropy as well as $\mathrm{g}_{\text {effective }}$ factor of 2.10. This parameter, determined from $\mathrm{hv} / \mathrm{bH}$, evidences a strong interaction between $\mathrm{Fe}^{3+}$ ions in $\mathrm{Fe}_{2} \mathrm{O}_{3}$, as its $\mathrm{g}$ factor was equivalent to that of a free electron. For all the spectra, the extension of the bands indicated greater magnetic anisotropy (Ma), following the trend $\mathrm{Fe}-\mathrm{MIO}<\mathrm{FeNi}-\mathrm{MIO}<\mathrm{FeCo}-\mathrm{MIO}$, in agreement with the values from the VSM data (Table 1).

The $\mathrm{g}$ factor of approximately 2.1 also indicated that $\mathrm{M}^{2+}$ was substituted in the ferrites $\left(\mathrm{MO} \cdot \mathrm{Fe}_{2} \mathrm{O}_{3}\right.$ ), as shown in the EPR spectrum of ferrites (Figure $5 \mathrm{~b}$, square and triangle lines). The iron oxides characteristic spectra consist of a single line with a width ranging from 700 to $6000 \mathrm{G}$ and a $\mathrm{g}$ factor with values between 2.00 and 10.00 , depending on the composition of the sample. The presence of spin coupled $\mathrm{Fe}^{2+}$ and $\mathrm{Fe}^{3+}$ ions in octahedral sites (ferromagnetic phase) is readily identified in the $\mathrm{X}$-ray diffraction pattern, but cannot be distinguished in the EPR spectrum at room temperature, maybe due to the relatively small crystal field splitting and superimposition of the energy levels or experimental resolution reflecting on signal broadening generating an envelope extending over the spin rotation network. Both events would preclude the observation of the $\mathrm{Fe}^{2+}$ resonance frequency, whose peak should appear at lower temperatures. $\mathrm{Fe}^{3+}$ is an ion with
$3 d^{5}$ configuration giving an effective spin of $5 / 2$ or $1 / 2$ depending on the ligand field.

The low field ground state $\left(6 S^{5 / 2}\right)$ with no orbital angular momentum and spin degeneracy of six times should result in extremely low spin interactions in the crystal field, and the $g$ values are very close to those expected for the free electron spin. ${ }^{43,44}$ The band broadening and shifting of the $\mathrm{g}$ factor can be assigned to the higher anisotropy of the material. The same happened for ferrites samples since the samples that showed fewer crystalline phases were those with larger anisotropies in their EPR spectra.

\section{Analysis of cytotoxicity}

Finally, toxicity tests are necessary when evaluating new materials or compounds that can be applied in many technological fields such as pigments, catalysts, and carriers of medical drugs. ${ }^{12}$ In applications such as these, the use of nontoxic materials is generally of supreme importance. Thus, an hemolysis assay was performed to give a preliminary indication of their cytotoxicity, and the results are shown in Figure 6. According to the data, none of the

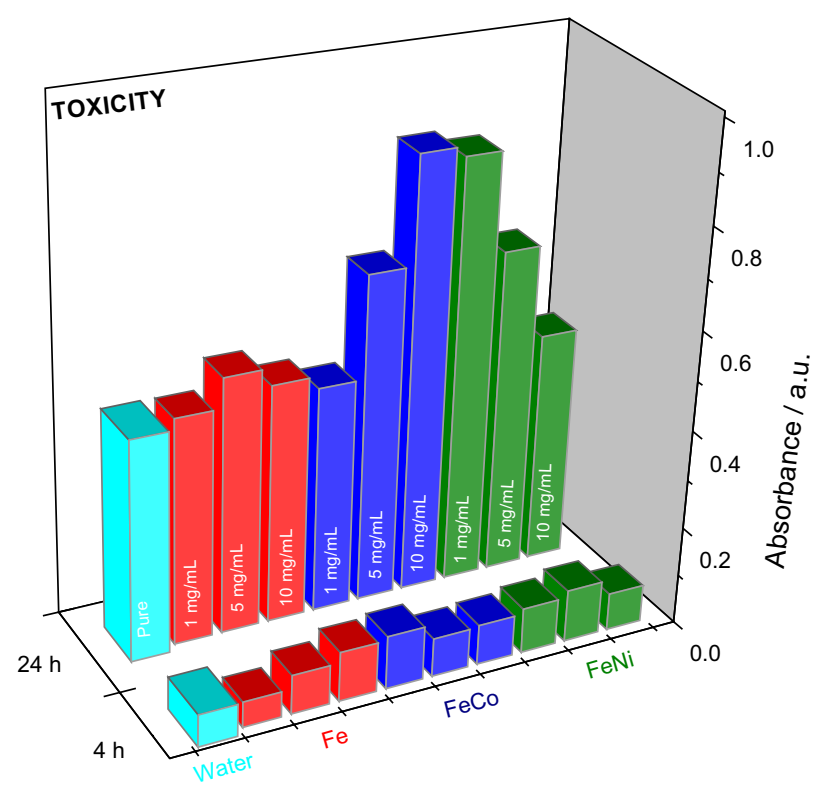

Figure 6. Cytotoxicity analysis of MIOs in which the maximum value recommended for nontoxic samples is an absorbance of 1.0 a.u. 
oxides reached the recommended limits in arbitrary units (1.0 a.u.). This analysis pointed to potential applications as carriers of drugs, as contrast materials for magnetic resonance measurements, and as miscible ferrofluids in both aqueous and nonpolar media. ${ }^{42}$

\section{Conclusions}

The method involved two steps (gelation and calcination) and proved feasible in preparing magnetic iron oxides with intrinsic properties determined by the nature of the transition metal ions involved $\left(\mathrm{Fe}^{2+}, \mathrm{Fe}^{3+}, \mathrm{Co}^{2+}, \mathrm{Co}^{3+}, \mathrm{Ni}^{2+}\right.$, etc.). SEM images and BET analysis show the formation of mesoporous materials with nanometric dimensions obtained by a singular synthesis route. The low magnetic properties of Fe-MIO is consistent with the fact that is largely constituted by hematite with less than $10 \%$ of magnetite. The difference between the magnetic properties and the degree of toxicity within the recommended limits put the MIOs a potential candidates for development of materials for application in the medical area as fluid or iron for image contrast.

\section{Acknowledgments}

The authors would like to thank the Capes Agency (No. 028/2009 and 063/2010), CNPq (Scholarship Researcher No. 305447/2013-0 and Grant No. 447902/2014-8), FINEP (No. 01.09.0393.00 and 01.12.0471.00), and Fundação Araucária. F. Q. Mariani and M. Dalpasquale thank the $\mathrm{PhD}$ scholarships granted by DS-CAPES. Thanks also go to C. A. Schwengber and UFPR/Palotina for BET analysis; to N. M. Khalil, Unicentro/Guarapuava, for cytotoxicity analysis; to IFUSP, for VSM curves, and to A. G. Mascarenhas for language support.

\section{References}

1. Wu, W.; Wu, Z.; Yu, T.; Jiang, C.; Kim, W.-S.; Sci. Technol. Adv. Mater. 2015, 16, 023501.

2. Oliveira, L. C. A.; Fabris, J. D.; Pereira, M. C.; Quim. Nova 2013, 36, 123.

3. Cabo, M.; Pellicer, E.; Rossinyol, E.; Estrader, M.; LópezOrtega, A.; Nogués, J.; Castell, O.; Suriñach, S.; Baró, M. D.; J. Mater. Chem. 2010, 20, 7021.

4. Pellicer, E.; Cabo, M.; López-Ortega, A.; Estrader, M.; Yedra, L.; Estradé, S.; Peiró, F.; Saghi, Z.; Midgley, P.; Rossinyol, E.; Golosovsky, I. V.; Mayoral, A.; Prades, J. D.; Suriñach, S.; Baró, M. D.; Sort, J.; Nogués, J.; Nanoscale 2013, 5, 5561.

5. Primc, D.; Makovec, D.; Nanoscale 2015, 7, 2688.

6. Homonnay, Z.; Vértes, A.; Mössbauer Spectroscopy of Sophisticated Oxides; Akadémiai Kiadó: Budapeste, 1997.
7. Walker, E.; Breen, M.; Apblett, A.; Chem. Mater. 1998, 4756, 1265.

8. Shin, J.; Lee, K. Y.; Yeo, T.; Choi, W.; Sci. Rep. 2016, 6, 21792.

9. Campos, E. A.; Stockler Pinto, D. V. B.; de Oliveira, J. I. S.; Mattos, E. D. C.; Dutra, R. D. C. L.; J. Aerosp. Technol. Manage. 2015, 7, 267.

10. Han, L.; Meng, H.; Wang, J.; Hu, Y.; Bao, W.; Chang, L.; Wang, H.; Ind. Eng. Chem. Res. 2016, 55, 5100.

11. Tan, Y.; Zhuang, Z.; Peng, Q.; Li, Y.; Chem. Mater. 2008, 5029.

12. Müller, M.; Villalba, J. C.; Mariani, F. Q.; Dalpasquale, M.; Lemos, M. Z.; Gonzalez Huila, M. F.; Anaissi, F. J.; Dyes Pigm. 2015, 120, 271.

13. Huang, C.; Zhang, H.; Sun, Z.; Liu, Z.; Sci. China Chem. 2010 , 53,1502 .

14. Dalpasquale, M.; Mariani, F. Q.; Müller, M.; Anaissi, F. J.; Dyes Pigm. 2016, 125, 124.

15. http://www.omicsonline.org/scientific-reports/srep550.php, accessed in October 2016.

16. Darder, M.; López-Blanco, M.; Aranda, P.; Leroux, F.; RuizHitzky, E.; Chem. Mater. 2005, 17, 1969.

17. Winkleman, A.; Bracher, P. J.; Gitlin, I.; Whitesides, G. M.; Chem. Mater. 2007, 19, 1362.

18. Santana, G. P.; Ramos, A. M.; Fabris, J. D.; Quim. Nova 2008, $31,430$.

19. Locatelli, G.; da Silva, G. D.; Finkler, L.; Finkler, C. L. L.; Biotechnology 2012, 11, 29.

20. Ur'yash, V. F.; Gruzdeva, A. E.; Kokurina, N. Y. Y.; Grishatova, N. V.; Faminskaya, L. A.; Polym. Sci., Ser. A 2007, 49, 1020.

21. Sarkar, S.; Guibal, E.; Quignard, F.; SenGupta, A. K.; J. Nanopart. Res. 2012, 14, 715.

22. Luque, R.; Varma, R. S.; Sustainable Preparation of Metal Nanoparticles: Methods and Applications; Luque, R.; Varma, R. S., eds.; Royal Society of Chemistry: Cambridge, 2012, p. 230.

23. Andrade, Â.; Fabris, J.; Domingues, R.; Pereira, M.; Curr. Pharm. Des. 2015, 21, 5417.

24. Andrade, Â. L.; Valente, M. A.; Ferreira, J. M. F.; Fabris, J. D.; J. Magn. Magn. Mater. 2012, 324, 1753.

25. Paiva, D. L.; Andrade, A. L.; Pereira, M. C.; Fabris, J. D.; Domingues, R. Z.; Alvarenga, M. E.; Hyperfine Interact. 2015, $232,19$.

26. Guo, L.; Arafune, H.; Teramae, N.; Langmuir 2013, 29 , 4404.

27. Paterson, E.; Clay Miner. 1999, 34, 209.

28. Sayed, F. N.; Polshettiwar, V.; Sci. Rep. 2015, 5, 9733.

29. Jacintho, G. V. M.; Brolo, A. G.; Corio, P.; Suarez, P. A. Z.; Rubim, J. C.; J. Phys. Chem. C 2009, 4, 7684.

30. Wang, Z.; Liu, X.; Lv, M.; Chai, P.; Liu, Y.; Meng, J.; J. Phys. Chem. B 2008, 4, 11292.

31. Hanesch, M.; Geophys. J. Int. 2009, 177, 941. 
32. Tong, L.; Ramser, K.; Kall, M. In Raman Spectroscopy for Nanomaterials Characterization; Kumar, C. S. S. R., ed.; Springer Berlin Heidelberg: Berlin, Heidelberg, 2012, p. 507.

33. de Faria, D. L. A.; Silva, S. V.; de Oliveira, M. T.; J. Raman Spectrosc. 1997, 28, 873.

34. Himcinschi, C.; Vrejoiu, I.; Salvan, G.; Fronk, M.; Talkenberger, A.; Zahn, D. R. T.; Rafaja, D.; Kortus, J.; J. Appl. Phys. 2013, $113,084101$.

35. Gilbert, B.; Frandsen, C.; Maxey, E.; Sherman, D.; Phys. Rev. B 2009, 79, 035108 .

36. Sherman, D. M.; Waite, T. D.; Am. Mineral. 1985, 70, 1262.

37. Martinez, A. I.; Garcia-Lobato, M. A.; Perry, D. L. In Research in Nanotechnology Developments; Barrañón, A., ed.; Nova Science Publishers, Inc.: New York, 2009, ch. 17, p. 183.

38. Han, D. H.; Wang, J. P.; Luo, H. L.; J. Magn. Magn. Mater. 1994, 136, 176.

39. Itoh, H.; Sugimoto, T.; J. Colloid Interface Sci. 2003, 265, 283.

40. Yang, Y.; Yi, J. B.; Huang, X. L.; Xue, J. M.; Ding, J.; IEEE Trans. Magn. 2011, 47, 3340.
41. Krajewski, M.; Malolepszy, A.; Stobinski, L.; Lewinska, S.; Slawska-Waniewska, A.; Tokarczyk, M.; Kowalski, G.; Borysiuk, J.; Wasik, D.; J. Supercond. Novel Magn. 2014, 4.

42. Cotica, L. F.; Freitas, V. F.; Silva, D. M.; Honjoya, K. K.; Honjoya, K. K.; Santos, I. A.; Fontanive, V. C. P.; Khalil, N. M.; Mainardes, R. M.; Kioshima, E. S.; Guo, R.; Bhalla, A. S.; J. Nano Res. 2014, 28, 131.

43. Koksharov, Y. A.; Pankratov, D. A.; Gubin, S. P.; Kosobudsky, I. D.; Beltran, M.; Khodorkovsky, Y.; Tishin, A. M.; J. Appl. Phys. 2001, 89, 2293.

44. Cao, X.; Gu, L.; Nanotechnology 2005, 16, 180.

Submitted: July 3, 2016

Published online: November 3, 2016

FAPERGS/CAPES has sponsored the publication of this article. 